\title{
Can markers of collagen turnover or other biomarkers contribute to the diagnostics of heart failure with normal left ventricular ejection fraction?
}

\author{
Jaroslav Meluzina, Josef Tomandl ${ }^{b}$, Helena Podrouzkovaa , Zdenka Gregorovaa, Vladimir Soskaa ${ }^{\mathrm{cd}}$, Petr Dobsake, \\ Ladislav Pecen ${ }^{f}$, Radka Stepanova ${ }^{f}$
}

\begin{abstract}
Aims. Plasma levels of some biomarkers and markers of collagen turnover may reflect myocardial structural abnormalities associated with diastolic dysfunction. The aim of this study was to determine whether these markers could contribute to the diagnostics of heart failure with normal ejection fraction (HFNEF).

Methods and Results. 91 patients with exertional dyspnea and normal left ventricular ejection fraction and 20 healthy controls underwent plasma analysis of markers of collagen turnover and other biomarkers, spirometry, and resting and exercise echocardiography. 38 patients with dyspnea had evidence of HFNEF, diagnosed at the early stage. Compared to the remaining patients, those with HFNEF had a significantly higher plasma levels of carboxy-terminal telopeptide of collagen type I (median $4.5 \mu \mathrm{g} / \mathrm{L}$ vs. $3.5 \mu \mathrm{g} / \mathrm{L}, P<0.05$ ) and big endothelin (median $1.1 \mathrm{pmol} / \mathrm{L}$ vs $0.9 \mathrm{pmol} / \mathrm{L}, P<0.05$ ). Univariate logistic regression analysis revealed a significant association between HFNEF and the following biomarkers: big endothelin, amino-terminal propeptide of type III procollagen (PIIINP), and matrix metalloproteinase-2 (MMP-2). However, none of these biomarkers independently contributed to the HFNEF diagnostics in a multivariate logistic regression analysis.

Conclusion Plasma levels of big endothelin, PIIINP, and MMP-2 were found to be associated with the presence of early diagnosed HFNEF. However, none of these biomarkers contributed independently to current noninvasive HFNEF diagnostics recommended by the European Society of Cardiology guidelines.
\end{abstract}

Key words: echocardiography, heart failure with normal ejection fraction, biomarkers

Received: May 29, 2012; Accepted with revision: December 4, 2012; Available online: February 14, 2013

http://dx.doi.org/10.5507/bp.2012.110

${ }^{a} 7^{\text {st }}$ Department of Internal Medicine-Cardioangiology, ICRC, St. Anne's University Hospital in Brno and Masaryk University, Brno, Czech Republic

${ }^{b}$ Department of Biochemistry, Faculty of Medicine, Masaryk University

'Department of Clinical Biochemistry, St. Anne's University Hospital in Brno and Masaryk University

${ }^{d} 2^{\text {nd }}$ Department of Internal Medicine, St. Anne's University Hospital in Brno and Masaryk University

eDepartment of Sports Medicine and Rehabilitation, Masaryk University

${ }^{f} I C R C$, St. Anne's University Hospital in Brno

Corresponding author: Jaroslav Meluzin, e-mail:jaroslav.meluzin@fnusa.cz

\section{INTRODUCTION}

Heart failure with normal left ventricular ejection fraction (HFNEF) is a syndrome associated with significant morbidity and mortality ${ }^{1}$. Its noninvasive diagnostics includes a history of resting or exercise-induced dyspnea, the presence of a nondilated left ventricle with a normal ejection fraction, and evidence of diastolic dysfunction ${ }^{2}$. The noninvasive diagnostics of left ventricular (LV) diastolic dysfunction relies on the analysis of natriuretic peptides and on parameters obtained from 2-dimensional and Doppler echocardiography ${ }^{2}$. Although a diagnostic approach utilizing parameter combinations appears superior to the application of only individual markers of diastolic dysfunction ${ }^{3.5}$, the noninvasive HFNEF diagnostics still has limitations ${ }^{6}$. At present, the major risk factors for HFNEF are aging, hypertension, and diabetes mellitus; i.e. diseases or states frequently associated with disturbances in collagen I and III turnover ${ }^{7-16}$. The serum or plasma level abnormalities of markers of collagen turn- over have been found to be related to increases in myocardial fibrosis s,15-17 $^{8}$ and to the development of diastolic dysfunction $^{13,14,17,18}$ and HFNEF (ref. ${ }^{10-12,19,20}$ ). Thus, the evidence of abnormalities in collagen synthesis and/or degradation, reflected by changes in plasma or serum levels of various markers of collagen turnover, may add new and worthwhile diagnostic and/or prognostic information ${ }^{10-12,19,20}$. Similarly, myocardial structural abnormalities and/or hemodynamic disturbances accompanying diastolic dysfunction may induce plasma level changes of various other biomarkers, the elevation of which may also add important diagnostic and/or prognostic information $^{21}$. The aims of this study were 1 , to analyze the plasma levels of markers of collagen turnover and of other biomarkers in patients with unexplained dyspnea with or without evidence of HFNEF and in healthy controls, and 2, to determine whether any of these markers might contribute independently to noninvasive HFNEF diagnostics. 


\section{MATERIALS AND METHOD}

\section{Study population}

This study is an extension of our previously published project on the role of exercise echocardiography in the diagnostics of HFNEF in patients with unexplained dyspnea $^{22}$ ( 76 of the total 111 subjects participated in both projects). The 91 patients presented in this study were selected from a cohort of patients who were referred to St. Anne's University Hospital in Brno (Brno, Czech Rep.) between April 2009 and February 2012 for elective invasive or CT coronary angiography to exclude coronary artery disease (CAD). The patients suffered from no or atypical chest discomfort, but the limiting symptom was exertional dyspnea. Patients with no coronary atherosclerosis or with only a mild insignificant coronary artery stenosis (luminal diameter narrowing $<40 \%$ ), with no history of myocardial infarction, no congenital or valvular heart disease, and no cardiomyopathy, renal, liver, lung, and metabolic bone disease were screened. The control group comprised patients with atypical chest discomfort but without exertional dyspnea, in whom invasive $(\mathrm{n}=11)$ or $\mathrm{CT}(\mathrm{n}=1)$ coronary angiography excluded CAD, and an additional 8 asymptomatic healthy volunteers. None of the controls suffered from cardiovascular disease or any other disease predisposposic to diastolic dysfunction (hypertension, diabetes mellitus, and hyperlipoproteinemia). Initially, all patients and controls underwent clinical and laboratory examination, spirometry, and baseline echocardiography at rest. Only those clinically stable, without renal, liver, and respiratory insufficiency or anemia entered this study. Echocardiography was used to confirm normal LV EF ( $\geq 50 \%$ ) and exclude any wall motion abnormality, previously unrecognized valvular or congenital heart disease, and cardiomyopathy. Spirometry was used to exclude any previously unrecognized respiratory disease (forced expiratory volume in $1 \mathrm{~s}$, forced vital capacity, and their ratio, all had to reach values $\geq 70 \%$ of predicted normal values).

All patients and controls gave their written consent to the investigations. The study complied with the Declaration of Helsinki and was approved by the ethics committee at St. Anne's University Hospital in Brno.

\section{Laboratory examination}

For biochemical analyses, blood samples were obtained from all the subjects after an overnight fasting before the resting and exercise echocardiography. To exclude anemia and renal or liver insufficiency, a complete blood count, serum creatinine, alanine aminotransferase, aspartate aminotransferase, bilirubin, and alkaline phosphatase were assayed. To diagnose HFNEF, N-terminal pro-B-type natriuretic peptide (NT-proBNP) plasma levels were measured by an immunoassay method with the Elecsys 2010 analyzer (Roche, Basel, Switzerland).

In addition, plasma levels of the following biomarkers and markers of collagen turnover were analyzed: carboxyterminal propeptide of procollagen type I (CICP), amino-terminal propeptide of type III procollagen (PIIINP), carboxy-terminal telopeptide of collagen type I (CITP), matrix metalloproteinase-2 (MMP-2), matrix metalloproteinase-9 (MMP-9), tissue inhibitor of matrix metalloproteinases type 1 (TIMP-1), homocysteine, cysteine, cysteinylglycine, glutathione, and big endothelin. Blood samples for markers of collagen turnover and biomarkers were placed in tubes containing EDTA or heparin. The plasma was separated by centrifugation and stored in a deep freeze at $-75{ }^{\circ} \mathrm{C}$ until analyzed. In heparin plasma, CICP (Quidel Corp., CA, USA), MMP-2 (R\&D Systems Inc., MN, USA), MMP-9 (R\&D Systems Inc., MN, USA), and TIMP-1 (R\&D Systems Inc., MN, USA) were measured. PIIINP (Orion Diagnostica Oy, Finland) and CITP (Orion Diagnostica Oy, Finland) were measured in EDTA plasma. All markers of collagen turnover were analyzed in duplicate by commercially available immunoassay kits according to manufacturer instructions. The maximal intra-assay variations for CICP, MMP-2, MMP-9, TIMP-1, PIINP, and CITP analyses were $6.8 \%, 5.8 \%, 2.9 \%, 5.0 \%$, $7.0 \%$, and $8.9 \%$, respectively.

Moreover, in EDTA plasma, big endothelin and total low molecular weight thiols (sum of reduced and oxidized forms of cysteine, homocysteine, cysteinylglycine, and glutathione) were analyzed by ELISA (Biomedica $\mathrm{GmbH}$, Austria) and by a high performance liquid chromatography with fluorescence detection (Shimadzu 10A series HPLC system, Shimadzu Corp., Japan), respectively. The plasma thiols were assayed according to Vester and Rasmusse ${ }^{23}$. The maximal intra-assay variations for big endothelin and total individual thiols analyses were $5 \%$ and $1.8 \%$, respectively.

\section{Echocardiography at rest and immediately after exercise}

Our echocardiographic examinations and data analyses were described previously ${ }^{22}$. Briefly, the examinations were performed using Vivid 7 and Vivid E9 (GE, Milwaukee, WI) with M3S and M5S transducers, respectively. Grayscale 2D images from apical 4- and 2-chamber views and parasternal short axis views at the base, at the level of papillary muscles, and at the apex were recorded. Transmitral, aortic, and pulmonary venous flows were recorded using pulsed Doppler echocardiography. Guided by color-coded 2D echocardiography, pulsed-wave Doppler tissue imaging (DTI) of mitral and tricuspid annular motion was recorded at 3 annular sites adjacent to the septum, lateral LV wall, and free right ventricular wall in the apical 4-chamber view. The narrow angle sector (30-40 degrees) was used to obtain Doppler tissue images of individual walls at the high frame rates $>150$ frames/s. Three to ten consecutive cardiac cycles were digitally stored for offline analysis using EchoPAC PC versions 6.1.0. and 108.1.5 (GE Medical Systems, Horten, Norway).

After resting echocardiography, symptom-limited exercise was performed by bicycle ergometry (Kettler X7, Siemens, Germany) in a sitting position using a continuous protocol with cycling at a rate of 50-60 rounds per minute. The initial workload of $25 \mathrm{~W}$ was increased by $25 \mathrm{~W}$ every 2 min until the limited symptoms appeared 
(dyspnea, leg fatigue, or general fatigue). Within $90 \mathrm{~s}$ after the exercise, with the patient in a position corresponding to the pre-exercise examination at rest, the following images were obtained: transmitral pulsed Doppler filling flow and Doppler tissue recordings of septal and lateral mitral annular motion and of tricuspid annular motion. The succession of post-exercise images was kept constant.

\section{Echocardiographic data}

Echocardiographic data analyses were performed according to the recommendations of the American Society of Echocardiography and the European Association of Echocardiography ${ }^{24}$. LV mass was estimated according to the Devereux formula ${ }^{25}$. From conventional pulsed-wave Doppler recordings of mitral valve inflow, the following parameters were assessed: peak early (E) and late (A) diastolic transmitral flow velocities, early filling deceleration time (DT), and A-wave duration (Ad). The duration of atrial reversal flow (ARd) was determined from pulmonary venous flow and the difference between ARd and Ad (ARd - Ad) was calculated. To determine peak systolic $\left(\mathrm{s}^{\prime}\right)$, early ( $\left.\mathrm{e}^{\prime}\right)$ and late (a') mitral annular velocities, the values obtained at septal and lateral sides of the mitral annulus were averaged. E, A, DT, and tissue Doppler velocities were analyzed both at rest and immediately after the end of exercise (exe). The data are presented as a mean of 3-6 consecutive heart cycles in patients with sinus rhythm or as a mean of 4-10 heart cycles in patients with atrial fibrillation. All echocardiographic measurements were performed by one experienced observer (JM). The intraobserver variability of this reader have been published ${ }^{22}$; they did not exceed 5\% for either transmitral flow parameters or Doppler tissue annular velocities.

\section{Definition of HFNEF}

Patients were considered to have HFNEF, if they had evidence of HFNEF assessed under resting conditions or were found to have isolated, only exercise-induced HFNEF. The presence of HFNEF under resting conditions was defined according to the algorithm published by experts of the Heart Failure and Echocardiography Associations of the European Society of Cardiology ${ }^{2}$ (ESC). Because a significant proportion of patients were found to have isolated, only exercise-induced HFNEF $\left(\right.$ ref. $\left.{ }^{26}\right)$, exercise was performed by all the patients. Isolated, only exercise-induced HFNEF was defined as exercise-induced dyspnea and an exercise increase in $\mathrm{E} / \mathrm{e}^{\prime}$ $>15$ or E/e'-sept ( $\mathrm{e}^{\prime}$ measured at the septal annular corner) $>13$ (ref. $\left.{ }^{27}\right)$. Based on these definitions, patients with exertional dyspnea were divided into patients without evidence of HFNEF (Group A2) and those with evidence of HFNEF (Group A1) determined under resting conditions and/or during exercise.

\section{Statistical analysis}

The baseline parameters, echocardiographic data, and biomarkers were analyzed descriptively and compared between the groups. Univariate and multivariate logistic regression were used to determine predictors and independent predictors of HFNEF.
Because the assumption of normal distribution was markedly violated for most continuous parameters (Shapiro-Wilk's test), nonparametric analyses were performed and appropriate descriptive statistics were used for the presentation of data as follows: absolute and relative frequencies for nominal parameters, and median, lower quartile (Q1) and upper quartile (Q3) for continuous parameters. For the comparison of all three groups (A1, A2, and $\mathrm{B}$ ) in continuous parameters, the Kruskal-Wallis test was conducted. For the detailed mutual comparison of the groups, the Wilcoxon Rank Sum test was performed. The Chi-square test was applied to compare the groups in nominal data.

The association between potential risk factors and HFNEF was analyzed via a univariate logistic regression model, where logistic regression coefficients with standard errors (SE) and p-values are presented together with the Odds Ratios (OR) and their 95\% confidence intervals. For the parameters with potential predictive power (providing at least $P<0.10$ in univariate logistic regression), various multivariate models (including significant echocardiographic parameters as the stable part of the model) were used to explore the predictive power of the tested biomarkers. Correlations of plasma biomarker levels with the E/e' ratio, NT-proBNP, and exercise tolerance in patients with evidence of HFNEF were evaluated via the calculation of the Spearman correlation coefficients $\left(\mathrm{r}_{\mathrm{s}}\right)$. Results with $P$-value $<0.05$ were considered statistically significant.

\section{RESULTS}

Of the 105 patients with exertional dyspnea initially screened, 14 patients were excluded. Nine had evidence of lung disease on spirometry; the remaining patients were found to have a significant tricuspid regurgitation, aortic regurgitation, anemia, poor quality of echocardiography, or $\mathrm{LV} \mathrm{EF}<50 \%$. Of the 22 controls screened, one subject was excluded because of LV hypertrophy and one for frequent atrial extrasystoles. Thus, the final cohort analyzed consisted of 91 patients with a history of exertional dyspnea (Group A) and 20 healthy controls (Group B). All group A patients developed dyspnea during exertion, mostly combined with general fatigue or leg fatigue. Of those, 38 fulfilled the criteria for HFNEF diagnosis (Group A1); the remaining 53 patients were free of HFNEF (Group A2). In 31 of the A1 patients, a diagnosis of HFNEF had already been made on the basis of NTproBNP and echocardigraphic results obtained at rest; the remaining 7 patients had isolated, only exercise-induced HFNEF (exercise-induced E/e' > 15 or E/e' at the septal annular corner $>13$ with no evidence of HFNEF under resting conditions). None of the HFNEF patients exhibited signs of heart decompensation on physical examination (rales on lung auscultation, neck vein distension, bilateral ankle edema, pleural effusion, etc.) and none was in NYHA functional class IV or had previously been hospitalized for heart failure. Thus, Group A1 represented patients with an early diagnosis of HFNEF. The baseline 
clinical characteristics of Groups A1, A2, and B patients are demonstrated in Table 1.

\section{Echocardiographic results at rest and immediately after the end of exercise}

Table 2 shows echocardiographic data at rest and immediately after the end of exercise. Of the 2-dimensional echocardiographic results, LV EF was lower while the LVMI and LAVI were higher in Group A1 than in Group A2. Of the Doppler variables obtained at rest, Group A1 and $\mathrm{A} 2$ patients differed in $\mathrm{A}, \mathrm{E} / \mathrm{A}, \mathrm{e}^{\prime}, \mathrm{a}^{\prime}, \mathrm{s}^{\prime}$ and $\mathrm{E} / \mathrm{e}^{\prime}$. Of the Doppler variables obtained immediately after the end of exercise, Group A1 patients exhibited higher E-exe, A-exe, and E-exe/e'-exe, while e'-exe, a'-exe, and s'-exe were significantly lower. The differences in E, A, E/A, e', E/e' are expected and logical as, by definition, the pathology in these parameters is involved in the diagnostics of HFNEF according to the ESC guidelines.

\section{Collagen turnover markers and other biomarkers in patients studied}

Table 3 demonstrates plasma levels of collagen turnover markers and other biomarkers in patients with exertional dyspnea with or without HFNEF and in controls. The significant differences between Groups A1 and A2 were found only for CITP and big endothelin. Group A1 patients had higher plasma levels of TIMP-1 and big endothelin than the healthy controls.

\section{Potential contribution of collagen turnover markers or other biomarkers to the diagnostics of HFNEF}

Of the biomarkers listed in Table 3, big endothelin, PIIINP, and MMP-2 (Table 4) proved to be associated with the diagnosis of HFNEF in a univariate logistic regression analysis. However, none of the biomarkers was predictive of HFNEF in a multivariate logistic regression analysis (Table 5).

\section{Relationship of plasma biomarker levels to the severity of diastolic dysfunction and exercise tolerance in patients with HFNEF}

Of the biomarkers or markers of collagen turnover, MMP-9 correlated significantly with NT-proBNP, an indicator of the severity of heart failure (Table 6). However, even if significant, the correlation was weak and did not allow prediction of the severity of diastolic dysfunction. There was a weak negative correlation of homocysteine with exercise duration. None of the biomarkers correlated significantly with the E/e'.

Table 1. Baseline clinical and hemodynamic data in patients with exertional dyspnea with or without the evidence of heart failure with normal left ventricular ejection fraction and in healthy controls.

\begin{tabular}{|c|c|c|c|c|}
\hline & $\begin{array}{c}\text { Group A1 } \\
(\mathrm{n}=38)\end{array}$ & $\begin{array}{c}\text { Group A2 } \\
(\mathrm{n}=53)\end{array}$ & $\begin{array}{l}\text { Group B } \\
(\mathrm{n}=20)\end{array}$ & $P$-value \\
\hline \multicolumn{5}{|l|}{ Demographics } \\
\hline Age (years) & $69.5(62.0-74.0)^{\mathrm{a}}$ & $63.0(58.0-68.0)^{\mathrm{b}}$ & $63.0(58.5-66.0)^{\mathrm{b}}$ & 0.001 \\
\hline Males (\%) & $12(31.6 \%)$ & $15(28.3 \%)$ & $8(40.0 \%)$ & 0.638 \\
\hline Hypertension (\%) & $33(86.8 \%)$ & $49(92.5 \%)$ & - & 0.380 \\
\hline Diabetes (\%) & $12(31.6 \%)$ & $15(28.3 \%)$ & - & 0.736 \\
\hline Hyperlipidemia (\%) & $23(60.5 \%)$ & $23(43.4 \%)$ & - & 0.106 \\
\hline Obesity (\%) & $19(50.0 \%)$ & $21(39.6 \%)$ & $5(25 \%)$ & 0.170 \\
\hline $\operatorname{BMI}\left(\mathrm{kg} / \mathrm{m}^{2}\right)$ & $29.5(26.0-33.0)$ & $28.0(26.0-31.0)$ & $28.0(24.5-29.5)$ & 0.219 \\
\hline \multicolumn{5}{|l|}{ Medication } \\
\hline Diuretics (\%) & $20(52.6 \%)$ & $26(49.1 \%)$ & - & 0.737 \\
\hline Beta-blockers (\%) & $29(76.3 \%)$ & $29(54.7 \%)$ & - & 0.032 \\
\hline Hypolipidemics (\%) & $24(63.2 \%)$ & $28(52.8 \%)$ & - & 0.325 \\
\hline ACEi/ARB (\%) & $26(68.4 \%)$ & $36(67.9 \%)$ & - & 0.960 \\
\hline \multicolumn{5}{|l|}{ Natriuretic peptides } \\
\hline NT-proBNP (ng/L) & $250.7(167.5-544.0)^{\mathrm{a}}$ & $94.3(67.0-151.5)^{b}$ & $79.9(39.5-123.0)^{\mathrm{b}}$ & $<0.001$ \\
\hline \multicolumn{5}{|l|}{ Hemodynamics } \\
\hline Heart rate (bpm) & $70.5(62.0-79.0)^{\mathrm{a}}$ & $74.0(65.0-84.0)^{\mathrm{a}, \mathrm{b}}$ & $78.5(72.0-85.0)^{\mathrm{b}}$ & 0.045 \\
\hline Systolic BP (mmHg) & $130.0(120.0-150.0)^{\mathrm{a}}$ & $130.0(120.0-140.0)^{\mathrm{a}}$ & $120.0(115.0-130.0)^{\mathrm{b}}$ & 0.042 \\
\hline Diastolic BP (mmHg) & $82.5(80.0-95.0)$ & $80.0(80.0-90.0)$ & $80.0(80.0-82.5)$ & 0.158 \\
\hline \multicolumn{5}{|l|}{ Ergometry } \\
\hline Exercise duration (s) & $387.0(305.0-482.0)^{\mathrm{a}}$ & $463.0(382.0-527.0)^{\mathrm{b}}$ & $645.0(480.0-722.0)^{\mathrm{c}}$ & $<0.001$ \\
\hline
\end{tabular}

ACEi, angiotensin converting enzyme inhibitor; ARB, angiotensin receptor blocker; BMI, body mass index; BP, blood pressure; Group A1, patients with dyspnea and the evidence of heart failure with normal ejection fraction (HFNEF); Group A2, patients with dyspnea without the evidence of HFNEF; Group B, healthy controls; NT-proBNP, N-terminal pro-B-type natriuretic peptide. Data are presented as median (lower quartile-upper quartile) or number (\%). ${ }^{\text {acc }}$ Marks of mutual statistically significant difference between the compared variants $\mathrm{A} 1, \mathrm{~A} 2$, and $\mathrm{B}(P<0.05)$. 
Table 2. Echocardiographic results at rest and immediately after the end of exercise in patients with exertional dyspnea with or without the evidence of heart failure with normal left ventricular ejection fraction and in healthy controls.

\begin{tabular}{|c|c|c|c|c|}
\hline & $\begin{array}{c}\text { Group A1 } \\
(\mathrm{n}=38)\end{array}$ & $\begin{array}{c}\text { Group A2 } \\
(\mathrm{n}=53)\end{array}$ & $\begin{array}{l}\text { Group B } \\
(\mathrm{n}=20)\end{array}$ & $P$-value \\
\hline \multicolumn{5}{|c|}{ 2D-echocardiography } \\
\hline EDVI $\left(\mathrm{mL} / \mathrm{m}^{2}\right)$ & $45.0(39.0-54.0)$ & $43.0(38.0-50.0)$ & $45.0(40.5-49.5)$ & 0.717 \\
\hline ESVI $\left(\mathrm{mL} / \mathrm{m}^{2}\right)$ & $16.0(12.0-21.0)$ & $14.0(12.0-17.0)$ & $14.0(11.0-16.5)$ & 0.167 \\
\hline LV EF (\%) & $64.0(60.0-70.0)^{\mathrm{a}}$ & $67.0(65.0-72.0)^{\mathrm{b}}$ & $69.5(66.5-73.0)^{\mathrm{b}}$ & 0.016 \\
\hline $\operatorname{LVMI}\left(\mathrm{g} / \mathrm{m}^{2}\right)$ & $102.5(88.0-123.0)^{\mathrm{a}}$ & $87.0(77.0-99.0)^{\mathrm{b}}$ & $89.0(72.0-93.5)^{\mathrm{b}}$ & $<0.001$ \\
\hline LAVI $\left(\mathrm{mL} / \mathrm{m}^{2}\right)$ & $36.0(29.0-41.0)^{\mathrm{a}}$ & $28.0(24.0-34.0)^{\mathrm{b}}$ & $28.0(24.0-32.0)^{\mathrm{b}}$ & 0.001 \\
\hline \multicolumn{5}{|c|}{ LV Doppler results } \\
\hline $\mathrm{E}(\mathrm{cm} / \mathrm{s})$ & $77.5(67.0-94.0)$ & $73.0(64.0-84.0)$ & $70.0(61.5-80.0)$ & 0.179 \\
\hline E-exe $(\mathrm{cm} / \mathrm{s})$ & $107.5(94.0-126.0)^{\mathrm{a}}$ & $95.0(82.0-105.0)^{\mathrm{b}}$ & $96.0(83.5-102.5)^{b}$ & 0.005 \\
\hline $\mathrm{A}(\mathrm{cm} / \mathrm{s})$ & $92.0(79.0-105.0)^{\mathrm{a}}$ & $76.0(69.0-87.0)^{b}$ & $72.0(65.0-79.0)^{\mathrm{b}}$ & $<0.001$ \\
\hline A-exe $(\mathrm{cm} / \mathrm{s})$ & $103.0(92.0-121.0)^{\mathrm{a}}$ & $97.0(83.0-106)^{b}$ & $97.5(87.0-109.5)^{\mathrm{a}, \mathrm{b}}$ & 0.041 \\
\hline $\mathrm{E} / \mathrm{A}$ & $0.8(0.7-1.0)^{\mathrm{a}}$ & $0.9(0.9-1.1)^{b}$ & $1.0(0.9-1.1)^{\mathrm{b}}$ & 0.016 \\
\hline E-exe/A-exe & $1.0(0.9-1.2)$ & $1.0(0.9-1.2)$ & $0.9(0.8-1.1)$ & 0.826 \\
\hline DT (ms) & $189.0(167.0-208.0)^{\mathrm{a}}$ & $180.5(159.0-198.0)^{\mathrm{a}, \mathrm{b}}$ & $159.5(149.5-189.0)^{b}$ & 0.017 \\
\hline DT-exe (ms) & $138.0(114.0-160.0)$ & $146.0(126.0-156.0)$ & $137.0(129.0-147.0)$ & 0.643 \\
\hline Ard - Ad (ms) & $-10.0(-30.5-(-1.5))$ & $-14.0(-23.0-(-3.5))$ & $-10.5(-17.0-(-5.0))$ & 0.640 \\
\hline $\mathrm{e}^{\prime}(\mathrm{cm} / \mathrm{s})$ & $7.1(6.3-8.4)^{\mathrm{a}}$ & $9.5(8.2-11.0)^{\mathrm{b}}$ & $9.4(8.8-10.5)^{\mathrm{b}}$ & $<0.001$ \\
\hline$e^{\prime}-\operatorname{exe}(\mathrm{cm} / \mathrm{s})$ & $9.3(8.1-10.8)^{\mathrm{a}}$ & $12.7(11.4-14.1)^{\mathrm{b}}$ & $12.9(12.0-14.3)^{\mathrm{b}}$ & $<0.001$ \\
\hline $\mathrm{a}^{\prime}(\mathrm{cm} / \mathrm{s})$ & $9.8(8.4-11.0)^{\mathrm{a}}$ & $11.0(9.8-12.2)^{b}$ & $11.2(9.6-12.6)^{b}$ & 0.012 \\
\hline$a^{\prime}$-exe $(\mathrm{cm} / \mathrm{s})$ & $11.1(9.2-13.3)^{\mathrm{a}}$ & $12.7(11.0-14.4)^{\mathrm{b}}$ & $14.4(13.0-16.5)^{\mathrm{c}}$ & $<0.001$ \\
\hline $\mathrm{s}^{\prime}(\mathrm{cm} / \mathrm{s})$ & $7.6(7.0-8.2)^{\mathrm{a}}$ & $9.1(8.0-10.1)^{b}$ & $8.8(8.0-9.3)^{\mathrm{b}}$ & $<0.001$ \\
\hline $\mathrm{s}^{\prime}$-exe $(\mathrm{cm} / \mathrm{s})$ & $9.5(8.8-10.3)^{\mathrm{a}}$ & $12.3(10.7-13.6)^{b}$ & $13.9(12.5-15.5)^{\mathrm{c}}$ & $<0.001$ \\
\hline $\mathrm{E} / \mathrm{e}^{\prime}$ & $10.6(9.4-12.7)^{\mathrm{a}}$ & $7.9(6.6-9.0)^{b}$ & $7.0(6.0-8.9)^{\mathrm{b}}$ & $<0.001$ \\
\hline E-exe/e'-exe & $11.0(9.9-12.5)^{\mathrm{a}}$ & $7.2(6.5-8.8)^{\mathrm{b}}$ & $7.2(6.5-7.7)^{b}$ & $<0.001$ \\
\hline
\end{tabular}

A, peak late transmitral flow velocity; a', peak late diastolic annular velocity; Ad, duration of late transmitral filling wave; Ard, duration of atrial reversal flow; DT, deceleration time of E wave; E, peak early transmitral flow velocity; e', peak early diastolic annular velocity; EDVI, end-diastolic volume index; ESVI, end-systolic volume index; exe, values obtained immediately after the exercise; LAVI, left atrial volume index; LV EF, left ventricular ejection fraction; LVMI, left ventricular mass index; s', peak systolic annular velocity. Other abbreviations as in Table 1 . Data are presented as median (lower quartile-upper quartile).

${ }^{\mathrm{a}-\mathrm{c}}$ Marks of mutual statistically significant difference between the compared variants $\mathrm{A} 1, \mathrm{~A} 2$, and $\mathrm{B}(P<0.05)$.

Table 3. Collagen turnover markers and other biomarkers in patients with exertional dyspnea with or without the evidence of heart failure with normal left ventricular ejection fraction and in healthy controls.

\begin{tabular}{lcccc}
\hline & $\begin{array}{c}\text { Group A1 } \\
(\mathrm{n}=38)\end{array}$ & $\begin{array}{c}\text { Group A2 } \\
(\mathrm{n}=53)\end{array}$ & $\begin{array}{c}\text { Group B } \\
(\mathrm{n}=20)\end{array}$ & $P$-value \\
\hline PIIINP $(\mu \mathrm{g} / \mathrm{L})$ & $6.7(4.8-7.7)$ & $5.6(4.9-6.4)$ & $5.3(5.1-5.8)$ & 0.135 \\
CICP $(\mu \mathrm{g} / \mathrm{L})$ & $80.5(66.0-97.0)^{\mathrm{a}, \mathrm{b}}$ & $73.0(62.0-88.0)^{\mathrm{a}}$ & $94.5(74.0-113.0)^{\mathrm{b}}$ & 0.008 \\
CITP $(\mu \mathrm{g} / \mathrm{L})$ & $4.5(3.5-5.5)^{\mathrm{a}}$ & $3.5(3.1-4.5)^{\mathrm{b}}$ & $3.9(3.3-4.3)^{\mathrm{a}, \mathrm{b}}$ & 0.047 \\
MMP-2 $(\mu \mathrm{g} / \mathrm{L})$ & $170.0(153.0-214.0)^{\mathrm{a}, \mathrm{b}}$ & $162.0(144.0-185.0)^{\mathrm{a}}$ & $185.5(167.0-197.0)^{\mathrm{b}}$ & 0.035 \\
MMP-9 $(\mu \mathrm{g} / \mathrm{L})$ & $37.3(28.1-60.2)$ & $42.2(31.3-51.4)$ & $39.9(32.4-55.3)$ & 0.851 \\
TIMP-1 $(\mu \mathrm{g} / \mathrm{L})$ & $92.5(79.0-116.0)^{\mathrm{a}}$ & $84.0(76.0-102.0)^{\mathrm{a}, \mathrm{b}}$ & $75.0(70.5-91.5)^{\mathrm{b}}$ & 0.038 \\
Homocysteine $(\mu \mathrm{mol} / \mathrm{L})$ & $12.0(10.1-14.8)$ & $12.0(9.3-15.0)$ & $11.7(10.3-14.6)$ & 0.935 \\
Cysteine $(\mu \mathrm{mol} / \mathrm{L})$ & $319.5(281.0-359.0)$ & $314.0(278.0-345.0)$ & $298.5(267.0-337.5)$ & 0.498 \\
Cysteinylglycine $(\mu \mathrm{mol} / \mathrm{L})$ & $43.5(38.0-48.0)$ & $44.0(38.0-49.0)$ & $44.0(41.0-47.5)$ & 0.889 \\
Glutathione $(\mu \mathrm{mol} / \mathrm{L})$ & $2.6(1.4-3.3)$ & $2.9(2.2-3.3)$ & $2.7(2.1-3.1)$ & 0.567 \\
Big endothelin $(\mathrm{pmol} / \mathrm{L})$ & $1.1(0.9-1.3)^{\mathrm{a}}$ & $0.9(0.8-1.1)^{\mathrm{b}}$ & $0.9(0.7-1.1)^{\mathrm{b}}$ & 0.006 \\
\hline
\end{tabular}

CICP, carboxy-terminal propeptide of procollagen type I; CITP, carboxy-terminal telopeptide of collagen type I; MMP-2, matrix metalloproteinase-2; MMP-9, matrix metalloproteinase-9; PIIINP, amino-terminal propeptide of type III procollagen; TIMP-1, tissue inhibitor of matrix metalloproteinases type 1. Data are presented as median (lower quartile-upper quartile).

${ }^{\mathrm{a}-\mathrm{c}}$ Marks of mutual statistically significant difference between the compared variants $\mathrm{A} 1, \mathrm{~A} 2$, and $\mathrm{B}(P<0.05)$. 
Table 4. Association of potential risk factors with HFNEF as the risk end-point in a univariate logistic regression model.

\begin{tabular}{lcccc}
\hline Biomarkers & \multicolumn{2}{c}{$\begin{array}{c}\text { Coefficient } \\
(\text { SE; } P \text { level })\end{array}$} & \multicolumn{2}{c}{ OR } \\
& \multicolumn{2}{c}{$(95 \% \mathrm{CI})$} \\
\hline Big endothelin $(\mathrm{pmol} / \mathrm{L})$ & 1.703 & $(0.760 ; P=0.025)$ & 5.49 & $(1.24 ; 24.34)$ \\
PIIINP $(\mu \mathrm{g} / \mathrm{L})$ & 0.224 & $(0.101 ; P=0.027)$ & 1.25 & $(1.03 ; 1.53)$ \\
MMP-2 $(\mu \mathrm{g} / \mathrm{L})$ & 0.012 & $(0.006 ; P=0.050)$ & 1.01 & $(1.00 ; 1.02)$ \\
\hline
\end{tabular}

Abbreviations as in Table 3.

Table 5. Association of potential risk factors with HFNEF as the risk end-point in a multivariate logistic regression model.

\begin{tabular}{|c|c|c|c|c|}
\hline \multirow{2}{*}{$\begin{array}{l}\text { Parameters included in model } \\
\text { Null model (intercept only) }\end{array}$} & \multicolumn{2}{|r|}{$\begin{array}{l}\text { Coefficient } \\
(\mathrm{SE} ; P \text { level })\end{array}$} & \multicolumn{2}{|c|}{$\begin{array}{c}\text { Multivariate adjusted OR } \\
\qquad(95 \% \mathrm{CI})\end{array}$} \\
\hline & 3.707 & $(3.708 ; P=0.317)$ & & \\
\hline NT-proBNP > $200 \mathrm{ng} / \mathrm{L}$ & -2.197 & $(0.613 ; P<0.001)$ & 0.01 & $(0.00 ; 0.14)$ \\
\hline $\mathrm{LVMI}>100 \mathrm{~g} / \mathrm{m}^{2}$ & -1.282 & $(0.497 ; P=0.010)$ & 0.08 & $(0.01 ; 0.54)$ \\
\hline $\mathrm{E} / \mathrm{e}^{\prime}>8$ & -1.394 & $(0.551 ; P=0.011)$ & 0.06 & $(0.01 ; 0.53)$ \\
\hline $\mathrm{LAVI}>35 \mathrm{~mL} / \mathrm{m}^{2}$ & -0.938 & $(0.507 ; P=0.064)$ & 0.15 & $(0.02 ; 1.12)$ \\
\hline s' (continuous) & -0.625 & $(0.347 ; P=0.071)$ & 0.54 & $(0.27 ; 1.06)$ \\
\hline Big endothelin (pmol/L) & 1.748 & $(1.608 ; P=0.260)$ & 6.12 & $(0.26 ; 142.96)$ \\
\hline PIIINP $(\mu \mathrm{g} / \mathrm{L})$ & 0.381 & $(0.308 ; P=0.217)$ & 1.46 & $(0.80 ; 2.67)$ \\
\hline MMP-2 ( $\mu \mathrm{g} / \mathrm{L})$ & -0.012 & $(0.017 ; P=0.479)$ & 0.99 & $(0.96 ; 1.02)$ \\
\hline \multicolumn{5}{|l|}{ Overall model parameters } \\
\hline$-2 * \log ($ likelihood $)$ - null/final model & & $121.9 / 43.0$ & & \\
\hline$\chi^{2(\mathrm{df}=8)} ; P$ value & & $17.3 ; P=0.028$ & & \\
\hline
\end{tabular}

Abbreviations as in Tables 1, 2, and 3.

Table 6. Correlation of plasma biomarker levels with left ventricular filling pressure (E/e'), NT-proBNP, and exercise tolerance in patients with evidence of heart failure with normal left ventricular ejection fraction.

\begin{tabular}{lccc}
\hline & $\begin{array}{c}\mathrm{E} / \mathrm{e}^{\prime} \\
\mathrm{r}_{\mathrm{s}}(P)\end{array}$ & $\begin{array}{c}\text { NT-proBNP } \\
\mathrm{r}_{\mathrm{s}}(P)\end{array}$ & $\begin{array}{c}\text { Exercise duration } \\
\mathrm{r}_{\mathrm{s}}(P)\end{array}$ \\
\hline PIIINP $(\mu \mathrm{g} / \mathrm{L})$ & $0.08(0.653)$ & $0.28(0.099)$ & $-0.07(0.690)$ \\
CICP $(\mu \mathrm{g} / \mathrm{L})$ & $0.12(0.478)$ & $-0.07(0.675)$ & $0.09(0.591)$ \\
CITP $(\mu \mathrm{g} / \mathrm{L})$ & $0.27(0.104)$ & $0.21(0.213)$ & $-0.09(0.611)$ \\
MMP-2 $(\mu \mathrm{g} / \mathrm{L})$ & $0.24(0.141)$ & $0.29(0.074)$ & $-0.01(0.937)$ \\
MMP-9 $(\mu \mathrm{g} / \mathrm{L})$ & $-0.17(0.311)$ & $\mathbf{0 . 4 6 ( 0 . 0 0 4 )}$ & $-0.01(0.970)$ \\
TIMP-1 $(\mu \mathrm{g} / \mathrm{L})$ & $0.28(0.087)$ & $0.11(0.516)$ & $-0.14(0.386)$ \\
Homocysteine $(\mu \mathrm{mol} / \mathrm{L})$ & $0.20(0.239)$ & $0.31(0.060)$ & $-\mathbf{0 . 3 5}(\mathbf{0 . 0 3 0})$ \\
Cysteine $(\mu \mathrm{mol} / \mathrm{L})$ & $0.20(0.235)$ & $0.22(0.184)$ & $-0.25(0.129)$ \\
Cysteinylglycine $(\mu \mathrm{mol} / \mathrm{L})$ & $0.02(0.882)$ & $0.19(0.258)$ & $0.25(0.131)$ \\
Glutathione $(\mu \mathrm{mol} / \mathrm{L})$ & $0.02(0.920)$ & $0.14(0.388)$ & $-0.03(0.870)$ \\
Big endothelin $(\mathrm{pmol} / \mathrm{L})$ & $-0.01(0.947)$ & $-0.01(0.970)$ & $-0.21(0.213)$ \\
\hline
\end{tabular}

Abbreviations as in Tables 1, 2, and 3. P, level of significance; $r$, Spearman correlation coefficients.

\section{DISCUSSION}

Our study presents several important findings and has some priorities. We tested carefully selected patients without CAD, who met the ESC guidelines for the diagnosis of HFNEF. We studied patients at early stages of HFNEF, as none of them had clinical signs or history of heart failure decompensation, and 7 patients had isolated, only exercise-induced HFNEF. In a univariate logistic regression analysis, we found a significant association of big endothelin, PIIINP, and MMP-2 with the diagnosis of HFNEF. In addition, MMP-9 plasma levels correlated significantly with NT-proBNP, suggesting its relationship to the severity of diastolic dysfunction. However, none 
of the biomarkers contributed independently to the early HFNEF diagnostics in a multivariate logistic regression analysis.

\section{Noninvasive diagnostics of HFNEF}

Noninvasive diagnostics of HFNEF is difficult, and agreement between invasive and noninvasive results is not always optimal ${ }^{6}$. One step to improve diagnostic accuracy is the application of parameter combinations ${ }^{2-5}$. Dokainish et al. ${ }^{5}$ demonstrated in patients with preserved LV EF that adding left atrial volume index $>31 \mathrm{~mL} / \mathrm{m}^{2}$ to $\mathrm{E} / \mathrm{e}^{\prime}$ (when $\mathrm{E} / \mathrm{e}^{\prime}$ was in the gray zone of 8-13) significantly increased the accuracy of E/e' alone for the estimation of LV filling pressure. Recently, Kasner et al. ${ }^{4}$ demonstrated the utility of combining echocardiographic parameters with natriuretic peptides. They showed that estimation of NT-proBNP on top to mitral flow Doppler echocardiography represents an accurate strategy to diagnose diastolic dysfunction in HFNEF. However, despite the promising results of the diagnostic combinations mentioned above, it is likely that the identification of new biomarkers reflecting diastolic properties of the myocardium may further improve the accuracy of parameter combinations in the diagnostics of HFNEF.

\section{Structural myocardial abnormalities related to HFNEF}

One of the most important structural abnormalities in HFNEF is an increase in myocardial fibrosis ${ }^{28-30}$. Exaggerated myocardial accumulation of collagen has also been described in the setting of hypertension and/ or diabetes mellitus ${ }^{15,16,31,32}$, two basic risk factors for the development of HFNEF of nonischemic etiology. Querejeta et al. ${ }^{15}$ analyzed right septal endomyocardial biopsies in hypertensive patients to quantify collagen content. The authors demonstrated an increase in collagen volume fraction (CVF) and elevated serum carboxyterminal propeptide of procollagen type I (abbreviated as PIP) level. A significant correlation was found between CVF and serum PIP in all hypertensives. The same study group described that in hypertensive patients with LV hypertrophy, those with the evidence of heart failure had significantly greater CVF and higher PIP serum levels ${ }^{16}$. The amount of collagen types I and III analyzed from endomyocardial biopsies has been found to significantly influence LV diastolic function ${ }^{4}$, as reflected by changes in LV stiffness and by elevation of NT-proBNP plasma levels. In animal models of diastolic heart failure ${ }^{29}$, there was progress in LV fibrosis accompanied by the activation of MMP-9 and MMP-2, and by a significant elevation of mRNA levels of type I collagen, type III collagen, TIMP-1, and TIMP-2. Heymans et al. ${ }^{33}$ described in a group of patients with isolated aortic stenosis increased mRNA expression of collagen types I, III, and IV and transcripts involved in collagen synthesis. Collagen deposition was greater in aortic stenosis than in control subjects and was most pronounced in aortic stenosis patients with severe diastolic dysfunction. Cardiac TIMP-1 and -2 transcripts were significantly related to the degree of interstitial fibrosis and proportional to diastolic dysfunction. Similarly, experimentally-induced diabetes mellitus has been found to result in marked interstitial and perivascular fibrosis in the absence of coronary artery stenosis ${ }^{32}$. The fibrotic process was accompanied by worsening of myocardial function $^{32}$. Thus, there exists a close relationship between the severity of myocardial fibrosis, the severity of diastolic dysfunction, and the presence of HFNEF.

\section{Relationship of various biomarkers and indicators of increased collagen turnover to myocardial function and the diagnostics of HFNEF}

Numerous reports demonstrate that plasma or serum levels of myocardial collagen turnover biomarkers (PIIINP, CITP, PICP, MMP-1, TIMP-1) may be used as surrogate markers of myocardial fibrosis ${ }^{14,15,17,31}$ and are related to diastolic function ${ }^{9-14,17,18,20,34}$. A significant relationship between some of these markers and the diagnosis of HFNEF has already been documented. Barasch et al. ${ }^{19}$ described the increased prevalence of elevated CITP and PIIINP in patients with HFNEF. González et al. ${ }^{10}$ found increased levels of PICP, MMP1, and TIMP-1 in HFNEF patients and an independent association of TIMP-1 and the MMP-1/TIMP-1 ratio with pulmonary capillary wedge pressure. In hypertensive patients with a normal LV ejection fraction, Ahmed et al. ${ }^{20}$ found increased plasma levels of TIMP-1 in those with LV hypertrophy and signs of heart failure. Martos et al. ${ }^{11}$ studied 86 hypertensive patients. Those with HFNEF had greater serum levels of CITP, PIIINP, MMP-2, and MMP-9 than patients without HFNEF. Except for MMP-9, all these markers were greater in more severe phases of diastolic dysfunction. In the next study using receiver operating characteristic curve analysis, the same authors ${ }^{12}$ demonstrated that MMP-2 $(\mathrm{AUC}=0.91), \mathrm{CITP}(\mathrm{AUC}=0.83), \mathrm{PICP}(\mathrm{AUC}=0.82)$, MMP-9 (AUC $=0.79)$, and PIIINP $(\mathrm{AUC}=0.78)$ levels were significant predictors of HFNEF. Multivariate analysis identified 3 independent predictors of HFNEF (MMP2, MMP-9, and PIIINP). In a recent paper, Collier et al. ${ }^{35}$ analyzed fibro-inflammatory profiles across the spectrum of hypertensive heart disease. Compared to a cohort of patients with asymptomatic hypertension, hypertensive patients with HFNEF had increased inflammatory signals (interleukin 6, interleukin 8 , and monocyte chemoattractant protein 1), increased fibrotic signals (PIIINP and CITP), and increased matrix turnover signals (MMP-2 and MMP-9). Our study extends these projects in the analysis of big endothelin (indicator of vascular function and neurohumoral activity) and of homocysteine, cysteine, cysteinylglycine, and glutathione (agents affecting primarily myocardial oxidative stress). These agents are likely to have an impact on the development of myocardial hypertrophy and/or fibrosis ${ }^{36,37}$, two important determinants of LV diastolic dysfunction, and could teoretically contribute to the HFNEF diagnostics. In our study, we demonstrated a significant association of big endothelin, PIIINP, and MMP-2 with the diagnosis of HFNEF. In addition, MMP9 plasma levels correlated significantly with NT-proBNP, an indicator of the severity of diastolic dysfunction. However, neither the plasma levels of markers of collagen turnover nor the plasma levels of other biomarkers tested contributed independently to the HFNEF diagnostics in a 
multivariate analysis. The less tight relationship between biomarkers and the diagnosis of HFNEF in our study could be explained by the characteristics of our study population. In contrast to previously discussed reports ${ }^{10-12,35}$ that included patients who had previous hospitalizations for New Your Heart Association class IV heart failure or who fulfilled the Framingham criteria for heart failure diagnostics ${ }^{38}$, our study included patients with early stages (or less severe forms) of HFNEF. They had never required hospitalization for heart failure or parentheral diuretic therapy, had no signs of pulmonary congestion, and did not experience dyspnea at rest. The diagnosis of HFNEF was made according to the ESC guidelines ${ }^{2}$, i.e. it relied mainly on noninvasive evidence of the elevation of LV filling pressure. Some of our patients had only isolated exercise-induced HFNEF. In spite of the lack of the heart failure diagnostic accuracy of collagen turnover markers, our study shows the association between collagen turnover pathology and HFNEF and suggests the potential role of big endothelin in the pathophysiology of HFNEF.

\section{Study limitations}

There are several limitations to our study. The number of patients and healthy controls was relatively small. However, it was difficult to obtain age- and gendermatched controls, i.e. mainly women over 60 years of age without cardiovascular disease or risk factors. The recruitment of our patients, who had been mostly referred for coronary angiography to exclude CAD and frequently suffered from a number of risk factors for diastolic dysfunction, is likely to have affected the prevalence of HFNEF in our patients with exertional dyspnea. Finally, we analyzed biomarkers obtained from peripheral blood. For ethical reasons, it was not possible to investigate blood samples from the coronary sinus, which, theoretically, could be more contributory.

\section{CONCLUSIONS}

Of the markers of collagen turnover (CICP, PIIINP, CITP, MMP-2, MMP-9, and TIMP-1) and other biomarkers (big endothelin, cysteine, homocysteine, cysteinylglycine, and glutathione), the plasma levels of big endothelin, PIIINP, and MMP-2 were found to be associated with the presence of early diagnosed HFNEF. However, none of these biomarkers contributed independently to the current noninvasive HFNEF diagnostics recommended by the European Society of Cardiology guidelines.

\section{ABBREVIATIONS}

AUC, Area Under Curve; CAD, Coronary artery disease; CICP, Carboxy-terminal propeptide of procollagen type I; CITP, Carboxy-terminal telopeptide of collagen type I; CV, Coefficient of variation; CVF, Collagen volume fraction; DTI, Doppler tissue imaging; EDV, Enddiastolic volume; ESC, European Society of Cardiology;
ESV, End-systolic volume; HFNEF, Heart failure with normal left ventricular ejection fraction; LV, Left ventricular; MMP-2, Matrix metalloproteinase-2; MMP-9, Matrix metalloproteinase-9; NT-proBNP, N-terminal pro-B-type natriuretic peptide; OR, Odds ratio; PIIINP, Amino-terminal propeptide of type III procollagen; SE, Standard error; TIMP-1, Tissue inhibitor of matrix metalloproteinases type 1 .

\section{ACKNOWLEDGEMENT}

The study was supported by the European Regional Development Fund - Project FNUSA-ICRC (No. CZ.1.05/1.1.00/02.0123).

\section{CONFLICT OF INTEREST STATEMENT}

Author's conflict of interest disclosure: The authors stated that there are no conflicts of interest regarding the publication of this article.

\section{REFERENCES}

1. Owan $T E$, Hodge DO, Herges RM, Jacobsen SJ, Roger VL, Redfield MM. Trends in prevalence and outcome of heart failure with preserved ejection fraction. N Engl J Med 2006;355:251-9.

2. Paulus WJ, Tschope C, Sanderson JE, Rusconi C, Flachskampf FA, Rademakers FE, Marino P, Smiseth OA, De Keulenaer G, Leite-Moreira AF, Borbély A, Édes I, Handoko ML, Heymans S, Pezzali N, Pieske B, Dickstein K, Fraser AG, Brutsaert DL. How to diagnose diastolic heart failure: a consensus statement on the diagnosis of heart failure with normal left ventricular ejection fraction by the Heart Failure and Echocardiography Associations of the European Society of Cardiology. Eur Heart J 2007;28:2539-50.

3. Shuai XX, Chen YY, Lu YX, Su GH, Wang YH, Zhao HL, Han J. Diagnosis of heart failure with preserved ejection fraction: which parameters and diagnostic strategies are more valuable? Eur J Heart Fail 2011;13:737-45.

4. Kasner M, Gaub R, Westermann D, Kaplan H, Akpulat S, Steendijk $P$, Schultheiss HP, Tschope C. Simultaneous estimation of NT-proBNP on top to mitral flow Doppler echocardiography as an accurate strategy to diagnose diastolic dysfunction in HFNEF. Int J Cardiol 2011;149:23-9.

5. Dokainish H, Nguyen JS, Sengupta R, Pillai M, Alam M, Bobek J, Lakkis N. Do additional echocardiographic variables increase the accuracy of E/e for predicting left ventricular filling pressure in normal ejection fraction? An echocardiographic and invasive hemodynamic study. J Am Soc Echocardiogr 2010;23:156-61.

6. Penicka M, Bartunek J, Trakalova H, Hrabakova H, Maruskova M, Karasek J, Kocka V. Heart failure with preserved ejection fraction in outpatients with unexplained dyspnea. A pressure-volume loop analysis. J Am Coll Cardiol 2010;55:1701-10.

7. Alla F, Kearney-Schwartz A, Radauceanu A, Das Dores S, Dousset B, Zannad F. Early changes in serum markers of cardiac extra-cellular matrix turnover in patients with uncomplicated hypertension and type II diabetes. Eur J Heart Fail 2006;8:147-53.

8. Díez J, Panizo A, Gil MJ, Monreal I, Hernández M, Mindán JP. Serum markers of collagen type I metabolism in spontaneously hypertensive rats. Relation to myocardial fibrosis. Circulation 1996;93:102632.

9. Muller-Brunotte R, Kahan T, Lopez B, Edner M, González A, Díez J, Malmqvist K. Myocardial fibrosis and diastolic dysfunction in patients with hypertension: results from the Swedish Irbesartan Left Ventricular Hypertrophy Investigation versus Atenolol (SILVHIA), J Hypertens 2007;25:1958-66. 
10. González A, Lopez B, Querejeta R, Zubillaga E, Echeverría T, Díez J. Filling pressures and collagen metabolism in hypertensive patients with heart failure and normal ejection fraction. Hypertension 2010;55:1418-24.

11. Martos R, Baugh J, Ledwidge M, O’Loughlin Ch, Conlon C, Patle A Donnelly SC, McDonald K. Diastolic heart failure. Evidence of increased myocardial collagen turnover linked to diastolic dysfunction. Circulation 2007;115:888-95.

12. Martos R, Baugh J, Ledwidge M, O'Loughlin Ch, Murphy NF, Conlon C, Patle A, Donelly SC, McDonald K. Diagnosis of heart failure with preserved ejection fraction: improved accuracy with the use of markers of callagen turnover. Eur J Heart Fail 2009,11:191-7.

13. Poulsen $\mathrm{SH}$, Andersen NH, Heickendorff L, Mogensen CE. Relation between plasma amino-terminal propeptide of procollagen type III and left ventricular longitudinal strain in essential hypertension. Heart 2005;91:624-9.

14. Díez J, Laviades C, Mayor G, Gil MJ, Monreal I. Increased serum concentrations of procollagen peptides in essential hypertension. Relation to cardiac alterations. Ciculation 1995;91:1450-6.

15. Querejeta R, Varo N, López B, Larman M, Artinano E, Etayo JC, Martínez Ubago JL, Gutierrez-Stampa M, Emparanza Jl, Gil MJ, Monreal I, Mindán JP, Díez J. Serum carboxy-terminal propeptide of procollagen type I is a marker of myocardial fibrosis in hypertensive heart disease. Circulation 2000,101:1729-35.

16. Querejeta R, López B, González A, Sánchez E, Larman M, Martínez Ubago JL, Díez J. Increased collagen type I synthesis in patients with heart failure of hypertensive origin. Relation to myocardial fibrosis. Circulation 2004;110:1263-8.

17. Lindsay MM, Maxwell P, Dunn FG. TIMP-1. A marker of left ventricular diastolic dysfunction and fibrosis in hypertension. Hypertension 2002;40:136-41.

18. Tayebjee MH, Nadar SK, MacFadyen RJ, Lip GYH. Tissue inhibitor of metalloproteinase- 1 and matrix metalloproteinase- 9 levels in patients with hypertension. Am J Hypertens 2004;17:770-4.

19. Barasch E, Gottdiener JS, Aurigemma G, Kitzman DW, Han J, Kop WJ, Tracy RP. Association between elevated fibrosis markers and heart failure in the elderly. The cardiovascular health study. Circ Heart Fail 2009;2:303-10.

20. Ahmed SH, Clark LL, Pennington WR, Webb CS, Bonnema DD, Leonardi AH, McClure CD, Spinale FG, Zile MR. Matrix metalloproteinases/tissue inhibitors of metalloproteinases. Relation between changes in proteolytic determinants of matrix composition and structural, functional, and clinical manifestations of hypertensive heart disease. Circulation 2006;113:2089-96.

21. Sabatine MS, Morrow DA, de Lemos JA, Omland T, Sloan S, Jarolim P, Solomon SD, Pfeffer MA, Braunwald E. Evaluation of multiple biomarkers of cardiovascular stress for risk prediction and guiding medical therapy in patients with stable coronary disease. Circulation 2012;125:233-40.

22. Meluzín J, Sitar J, Křístek J, Prosecký R, Pešl M, Podroužková H, Soška V, Panovský R, Dušek L. The role of exercise echocardiography in the diagnostics of heart failure with normal left ventricular ejection fraction. Eur J Echocardiogr 2011;12:591-602.

23. Vester B, Rasmussen K. High performance liquid chromatography method for rapid and accurate determination of homocysteine in plasma and serum. Eur J Clin Chem Clin Biochem 1991;29:549-54.

24. Lang RM, Bierig M, Devereux RB, Flachskampf FA, Foster E, Pellikka P, Picard MH, Roman MJ, Seward J, Shanewise J, Solomon S, Spencer KT, Sutton MSJ, Stewart W. Recommendations for chamber quantification. Eur J Echocardiogr 2006;7:79-108.
25. Devereux RB, Alonso DR, Lutas EM, Gottlieb GJ, Campo E, Sachs I, Reichek N. Echocardiographic assessment of left ventricular hypertrophy: comparison to necropsy findings. Am J Cardiol 1986;57:4508.

26. Borlaug BA, Nishimura RA, Sorajja P, Lam CSP, Redfield MM. Exercise hemodynamics enhance diagnosis of early heart failure with preserved ejection fraction. Circ Heart Fail 2010;3:588-95.

27. Burgess MI, Jenkins C, Sharman JE, Marwick TH. Diastolic stress echocardiography: hemodynamic validation and clinical significance of estimation of left ventricular filling pressure with exercise. J Am Coll Cardiol 2006;47:1891-900.

28. Borlaug BA, Paulus WJ. Heart failure with preserved ejection fraction: pathophysiology, diagnosis, and treatment. Eur Heart J 2011;32:6709.

29. Nishikawa N, Yamamoto K, Sakata Y, Mano T, Yoshida J, Miwa T, Takeda H, Hori M, Masuyama T. Differential activation of matrix metalloproteinases in heart failure with and without ventricular dilatation. Cardiovasc Res 2003;57:766-74.

30. Kasner M, Westermann D, Lopez B, Gaub R, Escher F, Kühl U, Schultheiss HP, Tschope C. Diastolic tissue Doppler indexes correlata with the degree of collagen expression and cross-linking in heart failure and normal ejection fraction. J Am Coll Cardiol 2011;57:97785.

31. Jellis Ch, Martin J, Narula J, MarwickTH. Assessment of nonischemic myocardial fibrosis. J Am Coll Cardiol 2010;56:89-97.

32. Widyantoro B, Emoto N, Nakayama K, Anggrahini DW, Adiarto S, Iwasa N, Yagi K, Miyagawa K, Rikitake Y, Suzuki T, Kisanuki YY, Yanagisawa M, Hirata K. Endothelial cell-derived endothelin-1 promotes cardiac fibrosis in diabetic hearts through stimulation of endothelial-to-mesenchymal transition. Circulation 2010;121:2407-18.

33. Heymans $S$, Schroen B, Vermeersch P, Milting H, Gao F, Kassner A, Gillijns $\mathrm{H}$, Herijgers P, Flameng W, Carmeliet P, Van de Werf F, Pinto YM, Janssens $S$. Increased cardiac expression of tissue inhibitor of metalloproteinase- 1 and tissue inhibitor of metalloproteinase-2 is related to cardiac fibrosis and dysfunction in the chronic pressureoverloaded human heart. Circulation 2005;112:1136-44.

34. Ten Brinke EA, Witkowski TG, Delgado V, Klein P, Kolk M, Marsan NA, Klautz RJ, Van der Wall EE, Bax JJ, Van der Laarse A, Steendijk P. Myocardial collagen turnover after surgical ventricular restoration in heart failure patients. Eur J Heart Fail 2011;13:1202-10.

35. Collier P, Watson ChJ, Voon V, Phelan D, Jan A, Mak G, Martos R, Baugh JA, Ledwidge MT, McDonald KM. Can emerging biomarkers of myocardial remodelling identify asymptomatic hypertensive patients at risk for diastolic dysfunction and diastolic heart failure? Eur J Heart Fail 2011;13:1087-95.

36. Lombardi R, Rodriguez G, Chen SN, Ripplinger CM, Li W, Chen J, Willerson JT, Betocchi S, Wickline SA, Efimov IR, Marian AJ. Resolution of established cardiac hypertrophy and fibrosis and prevention of systolic dysfunction in a transgenic rabbit model of human cardiomyopathy through thiol-sensitive mechanisms. Circulation 2009;119:1398-407.

37. Joseph J, Washington A, Joseph L, Koehler L, Fink LM, Hauer-Jensen $\mathrm{M}$, Kennedy $\mathrm{RH}$. Hyperhomocysteinemia leads to adverse cardiac remodeling in hypertensive rats. Am J Physiol Heart Circ Physiol 2002;283:H2567-74.

38. Ho KKL, Pinsky JL, Kannel WB, Levy D. The epidemiology of heart failure: The Framingham Study. J Am Coll Cardiol 1993;22(Suppl):6A$13 \mathrm{~A}$. 